\title{
PEMBUATAN ALUR PELAYARAN KAPAL TAMBANG PADA SUNGAI MENGGUNAKAN MULTIBEAM ECHOSOUNDER (STUDI KASUS: SUNGAI MAHAKAM)
}

\author{
Yuwono $^{1}$, Eko Yuli Handoko ${ }^{2}$, Ahmad Ayyash Islami ${ }^{3}$ \\ 1,2,3 Departemen Teknik Geomatika, FTSLK-ITS, Kampus ITS Sukolilo, Surabaya, 60111 \\ e-mail : 1'yuwono@geodesy.its.ac.id, ${ }^{2}$ ekoyh@geodesy.its.ac.id, 3 ahmad.ayyash.geodesy@gmail.com³
}

\begin{abstract}
Abstrak
Pulau Kalimantan sebagai salah satu daerah penghasil batu bara terbesar di indonesia membutuhkan media transportasi yang dapat mendistribusikan hasil tambang batu bara. Media transportasi yang digunakan di Kalimantan salah satunya adalah Sungai Mahakam. Alur pelayaran harus dibuat untuk melewati Sungai Mahakam dengan aman, sehingga perlu dilakukan survei batimetri. Data batimetri yang didapat dari hasil survei akan dibuat alur pelayarannya dengan spesifikasi Standar Nasional Indonesia. Data yang digunakan adalah data batimetri dari PT.Seascape Surveys Indonesia. Data batimetri dikoreksi dengan pasang surut, Sound Velocity Profiler, gradien dan patch test. Kedalaman dari data batimetri mempunyai referensi terhadap EGM96 saat pengambilan data, lalu di transformasikan menjadi EGM08. Peta batimetri mempunyai referensi terhadap Lowest Low Water Level. Dari analisa peta batimetri Sungai Mahakam, dibuat alur pelayaran kapal Katingan dan kapal Straits Pheonix. Untuk kapal Katingan dibuat alur yang aman dengan spesifikasi kedalaman lebih dari 3,593 m dan spesifikasi lebar lebih dari 55,2m. Untuk kapal Straits Phoenix dibuat alur pelayaran dengan spesifikasi kedalaman lebih dari 5,128 m dan spesifikasi lebar lebih dari 112,7m. Berdasarkan peta batimetri yang dibuat, tidak terdapat alur yang aman untuk dilalui oleh kapal Katingan dan kapal Straits Phoenix.
\end{abstract}

Kata Kunci: Sungai Mahakam, Survei Batimetri, Multibeam Echosounder, Alur Pelayaran, Gradien

\begin{abstract}
Kalimantan Island is one of the largest coals producing regions in Indonesia which make mining companies in Kalimantan need transportation mode in which covers most of the mining areas. Water transportation is the answer that mining company need to transport mining products such as. The Mahakam River is the main water transportation medium used to connect areas that can not be traversed by land in Kalimantan. In order to prompt a safe transportation, a shipping line must be developed carefully. The shipping line is made based on bathymetric survey using a Multibeam Echosounder. Route were made based on bathymetric data. The shipping line is based on Indonesia national standard. For Katingan Ship, route was made with depth below 3.593 ms and width no more than $55.2 \mathrm{~m}$. As for Straits Pheonix Ship, route was made with depth below $5.128 \mathrm{~m}$ and width no more than $112.7 \mathrm{~ms}$. The data us ed in this research is provided by PT. Seascape Surveys Indonesia. Bathymetric data were corrected with tidal correction, sounds speed, water surface gradient and patch test. The depth during data acquisition refer to EGM96 however vertical reference in this research is EGMO8, thus a vertical transformation datum was performed to achieve the corrected depth.
\end{abstract}

Keywords: Mahakam River, Bathimetric Survey, Multibeam Echosounder, Shipping Line, Gradient 


\section{PENDAHULUAN}

Survey hidrografi menurut International Hydrographic Organization (IHO) adalah the branch of applied sciences which deals with the measurement and description of the physical features of oceans, seas, coastal areas, lakes and rivers, as well as with the prediction of their change over time, for the primary purpose of safety of navigation and in support of all other marine activities, including economic development, security and defense, scientific research, and environmental protection.

Dalam survei hidrografi digunakan sistem akustik. Sistem akustik sangat efektif untuk mengeksplorasi kenampakan bawah laut. The basic principle of sonar is to use sound to detect or locate objects, typically in the ocean. Saat ini teknologi akustik yang berperan dalam survei hidrografi adalah Multibeam Sonar. Multibeam echosounders, like other sonar systems, emit sound waves in the shape of a fan from directly beneath a ship's hull. These systems measure and record the time it takes for the acoustic signal to travel from the transmitter (transducer) to the seafloor (or object) and back to the receiver. Multibeam echosounder sangat efektif untuk survei kedalaman dikarenakan hasil yang diberikan cukup akurat. Peran multibeam echosounder cukup besar dalam penentuan alur pelayaran dikarenakan data utama yang dibutuhkan dalam pembuatan alur pelayaran adalah data kedalaman.

Salah satu bagian dari survei hidrografi adalah survei alur pelayaran. Alur pelayaran sangatlah dibutuhkan untuk memberikan informasi alur yang aman untuk dilewati oleh kapal. Dengan adanya alur ini, kemungkinan kapal karam dikarenakan membentur seabed (dasar perairan, dasar sungai, dasar laut) dapat dikurangi secara signifikan. Penentuan alur kapal tidak hanya dilakukan di perairan laut, namun juga dilakukan di sungai yang mempunyai peran penting dalam perputaran ekonomi Indonesia. Salah satu sungai tersebut adalah Sungai Mahakam.

Sungai Mahakam merupakan sungai terpanjang kedua di Pulau Kalimantan dan Indonesia dengan panjang $920 \mathrm{~km}$. Sungai Mahakam mempunyai peran penting dalam perekonomian masyarakat Kalimantan. Sungai ini digunakan sebagai alur transportasi utama di Kalimantan, pada tempat yang belum tersedia akses transportasi darat. Sampai dengan sekarang, masih ada 100 kelotok hilir-mudik di perairan
Sungai Mahakam. Salah satu peran Sungai Mahakam sebagai alur transportasi adalah sebagai media pengiriman hasil tambang batu bara perusahaan tambang di Kalimantan.

Kalimantan merupakan salah satu penghasil tambang batu bara terbesar di Indonesia, hal ini dapat dilihat dari Izin Usaha Pertambangan (IUP) luas area tambang batu bara yang cenderung meningkat setiap tahunnya. Dalam Provinsi Kalimantan Timur saja, tercatat 221 IUP dengan 803.855 ha luas area tambang batu bara pada tahun 2014, 219 IUP dengan 792.596 hektar (ha) pada tahun 2015 dan 246 IUP dengan 944.043 ha pada tahun 2016. Dengan hasil tambang batu bara yang melimpah, maka sungai Mahakam digunakan sebagai alur transportasi utama untuk mengirim hasil tambang batu bara dari satu lokasi menuju lokasi lainnya.

Dengan dibuatnya alur pelayaran Sungai Mahakam, diharapkan akan memudahkan navigasi kapal pengangkut batu bara untuk mencari alur pelayaran yang aman. Hal ini akan mengurangi tingkat kecelakaan lalu lintas air di Sungai Mahakam.

\section{METODOLOGI PENELITIAN}

\section{Lokasi Penelitian}

Lokasi penelitian ini berada di Kalimantan Timur, untuk koordinat tepatnya tidak dapat disebutkan disini, karena merupakan rahasia dari perusahaan PT. Seascape Survey Indonesia.

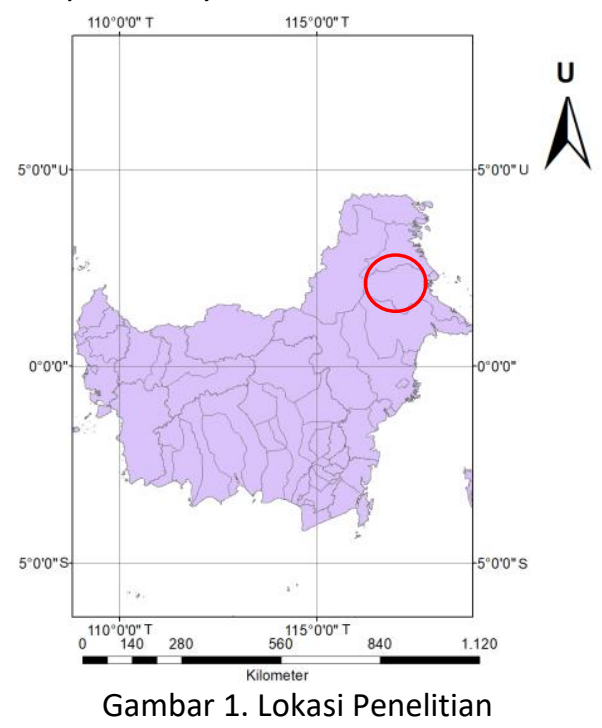

\section{Data dan Peralatan}

Data yang digunakan dalam penelitian ini adalah data Multibeam Echosounder, data pasang surut, 
data kecepatan suara, data Singlebeam echosounder dan Global Positioning System (GPS).

Peralatan yang digunakan dalam penelitian ini adalah EIVA Navisuite, EGM2008 Calculator, NimaEGM96 dan ArcGIS 10.5.

\section{Tahapan Penelitian}

Tahapan yang dilakukan pada penelitian ini adalah sebagai berikut.

- Tahap awal yang meliputi identifikasi masalah, studi literatur, selanjutnya pengambilan data, pengolahan data dan analisa, dan terkhir ditarik kesimpulan.

- Pengolahan data

Data multibeam difilter dari data spike. Selanjutnya dilakukan penggabungan beberapa data DTM. Data SVP, patch tes dan pasang suurut. Lakukan koreksi gradien. Ubah refensi chart datum dari EGM96 menjadi LLWL yang diambil dari pengukurang pasang surut selama 10 tahun. Selanjutnya data ini dibawa ke EGM08. Berikutnya data multibeam diplot pada peta.

Hitung gradien setiap $2 \mathrm{~km}$, selanjutnya dilakukan transformsi datum vertkal. Tahap terakhir adalah pembuatan alur pelayaran yaitu dengan memperhtikan spesifikasi kedalaman dan lebar alur pelayaran.

\section{HASIL DAN PEMBAHASAN}

\section{Ketelitian Pengukuran}

Pengukuran batimetri ini menggunakan perhitungan ketelitian dari standar IHO SP-44. Penelitian ini mempunyai klasifikasi survei orde 1. Dengan menggunakan 30 sampel titik, dihitung nilai ketelitian pada pengukuran ini. Nilai rata-rata ketelitian yang didapatkan adalah $0,43 m$ dengan standar deviasi 0,294.

\section{Pasang Surut Sungai}

Dari pengukuran pasang surut sungai selama 10 tahun dari rambu pasang surut di area penelitian, didapatkan data Lowest Low Water Level (LLWL) yang menjadi referensi kedalaman / chart datum (CD) dalam peta batimetri pada penelitian ini. Perhatikan Gambar 2 berikut.

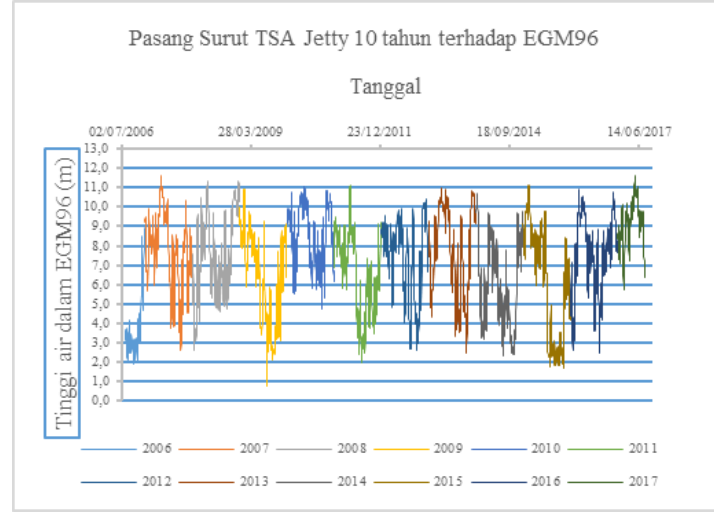

Gambar 2. Pasang Surut Sungai

Pada Gambar 2 didapatkan nilai LLWL sebesar $0,79 \mathrm{~m}$ diatas permukaan geoid. Nilai ini yang akan menjadi referensi kedalaman pada peta batimetri.

\section{Hasil Analisa Gradien}

Dengan menggunakan data singlebeam echosounder, GPS kinematik dan offset kapal didapatkan nilai gradien dari muka sungai. Perhatikan Gambar 3 berikut.

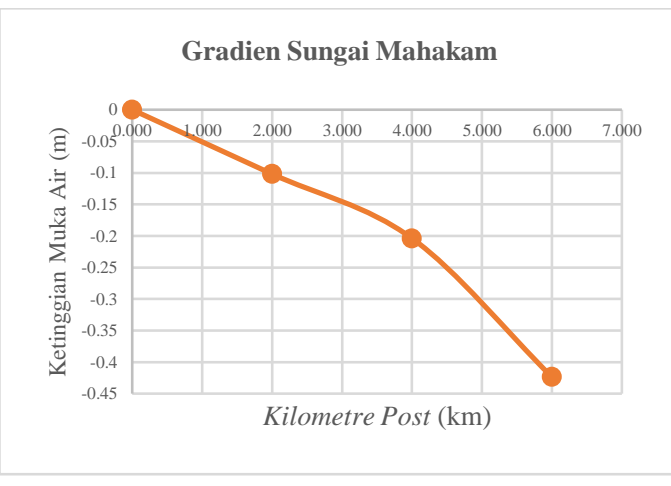

Gambar 3. Gradien Muka Air Sungai

Pada Gambar 3, penurunan muka air sungai dari Kilometer Post (KP) 0 hingga KP 6 adalah sebesar 0,423m. Dari nilai ini didapatkan nilai gradien sebesar 0,00007 .

\section{Transformasi Datum}

Nilai Digital Terrain Model (DTM) dari batimetri sungai yang sebelumnya mempunyai referensi EGM96 di transformasikan menjadi EGM08 dengan membandingkan perbedaan nilai undulasi dari kedua geoid tersebut. Perbedaan undulasi akan di masukkan ke dalam setiap titik batimetri. Perhatikan Gambar 4 berikut. 


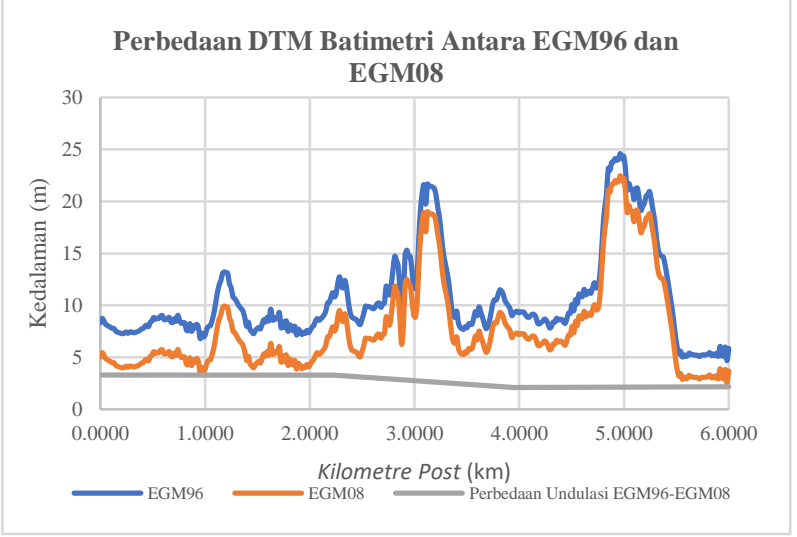

Gambar 4. Transformasi DTM Sungai

Dalam Gambar 4 merupakan topografi dari riverbed sungai di sepanjang garis KP. Garis biru menunjukkan nilai kedalaman saat masih bereferensi EGM96 sedangkan garis jingga menunjukkan nilai kedalaman setelah bereferensi EGM08. Garis abu-abu adalah perbedaan nilai undulasi dari EGM96 dengan EGM08. Setelah data batimetri di transformasikan akan didapatkan DTM akhir seperti Gambar 5 berikut.

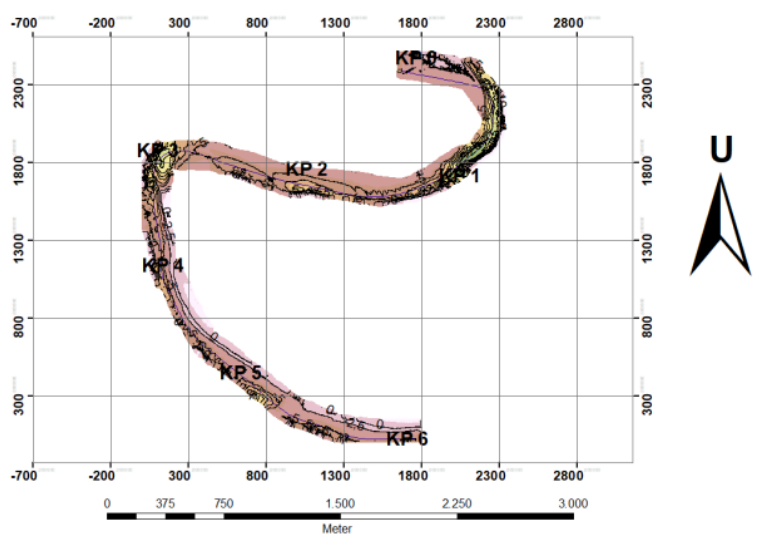

Gambar 5. DTM Akhir

\section{Pembuatan Alur Pelayaran}

Alur pelayaran dari Sungai Mahakam dibuat berdasarkan spesifikasi kapal yang akan berlayar. Dalam penelitian ini digunakan dua kapal barang (Bulk Carrier) yaitu kapal Katingan dan kapal Straits Phoenix. Untuk spesifikasi kapal Katingan dan kapal Straits Phoenix perhatikan Tabel 1 berikut.
Tabel 1. Spesifikasi Kapal

\begin{tabular}{cccccc}
\hline Nama & $\begin{array}{c}\text { Dead } \\
\text { Weight } \\
\text { Kapal } \\
\text { (DWT) } \\
\text { (ton) }\end{array}$ & $\begin{array}{c}\text { Length } \\
\text { Over } \\
\text { All } \\
(\mathrm{LOA}) \\
(\mathrm{m})\end{array}$ & $\begin{array}{c}\text { Lebar } \\
(\mathrm{m})\end{array}$ & $\begin{array}{c}\text { Draft } \\
\text { terendam } \\
\text { saat } \\
\text { bobot } \\
\text { maksimal } \\
(\mathrm{m})\end{array}$ & $\begin{array}{c}\text { Draft tidak } \\
\text { terendam } \\
\text { saat bobot } \\
\text { maksimal } \\
(\mathrm{m})\end{array}$ \\
\hline $\begin{array}{c}\text { Katingan } \\
\text { Straits } \\
\text { Phoenix }\end{array}$ & 336 & 30,51 & 12 & 2,4 & 0,6 \\
\hline
\end{tabular}

Dari Tabel 1 dibuat spesifikasi kedalaman alur pelayaran dan lebar alur pelayaran. Kapal Katingan mempunyai spesifikasi kedalaman sebesar 3,593m dan spesifikasi lebar alur sebesar $55,2 \mathrm{~m}$. Dari spesifikasi tersebut dibuat alur pelayarannya seperti pada Gambar 6 berikut.

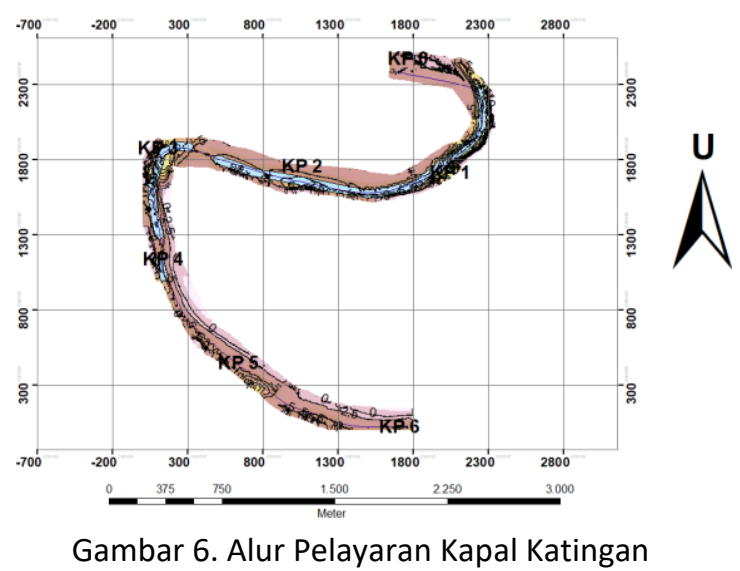

Dalam Gambar 6 alur pelayaran yang dapat dilewati kapal Katingan hanya pada KP 0,5- KP 2,5, KP 3 - KP 3,7 dan awal KP 4.

Untuk Kapal Straits Phoenix alur pelayaran yang dibuat mempunyai spesifikasi kedalaman sebesar $5,128 \mathrm{~m}$ dan spesifikasi lebar sebesar $112,7 \mathrm{~m}$. Alur pelayaran pada kapal Straits Phoenix dapat dilihat pada Gambar 7 berikut.

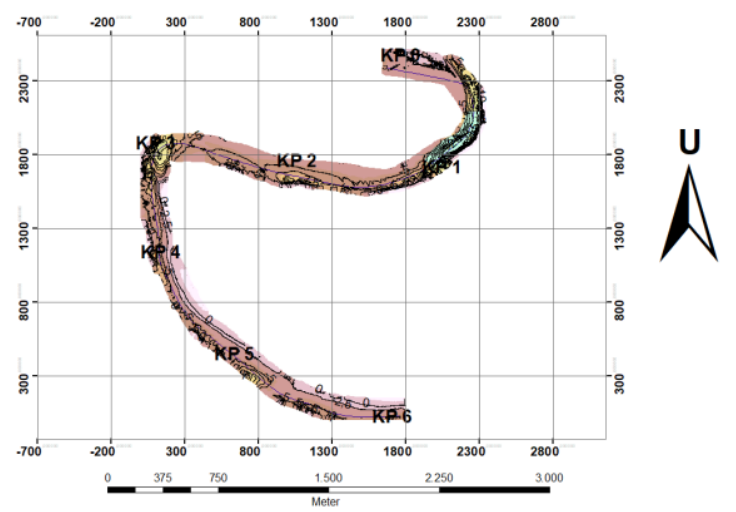

Gambar 7. Alur Pelayaran Kapal Straits Pheonix 
Dari Gambar 7 alur pelayaran yang dapat dilewati oleh kapal Straits Pheonix hanyalah pada KP 0,5-KP 1.

Berdasarkan analisa dari alur pelayaran kapal Katingan dan Straits Phoenix, dapat disimpulkan bahwa kapal Katingan hanya dapat melewati Sungai Mahakam pada penelitian ini di KP 0,5 - KP 2,5, KP 3 - KP 3,7 dan awal KP 4 . Dikarenakan tidak semua daerah aliran Sungai Mahakam dapat dilewati maka dapat disimpulkan tidak terdapat alur pelayaran yang aman untuk Kapal Katingan. Untuk kapal Straits Phoenix alur yang dapat dilewati hanya pada KP 0,5-KP 1 . Dari analisa tersebut dapat disimpulkan tidak ada alur pelayaran yang aman untuk kapal Straits Phoenix.

\section{DAFTAR PUSTAKA}

Djunarsah, E. \&. Poerbandono. (2005). Survei Hidrografi. Bandung: Penerbit Refika Aditama.

Godin, G. (1984). The Tide in Rivers. Kanada : University of New Brunswick.

IHO. (2005). Manual on Hydrography. Monaco: International Hydrographic Bureau.

IHO. (2008). IHO Standards for Hydrographics Surveys 5th Edition Special Publication No. 44. Monaco: International Hidrographic Bureau

IHO. (2011). TWLGLG4/4/11B. Monaco: International Hydrographic Bureau

Jong, D. (2002). Hydrography. Netherlands: Delft University Press

Kramadibrata, S. (2002). Perencanaan Pelabuhan. Bandung. PT Refika Aditama.

Lekkerkerk, H. J., Velden, R. V., Haycock, T., Jansen, P., Vries, R. D., Waalwijk, P. V., et al. (2006). Handbook of Offshore Surveying Volume One: Preparation \& Positioning. London: Clarkson Research Service Limited.

Parnum, lain., Paulus, J.W.S., Alexander N.G. (2014). A Comparison of Singlebeam and Multibeam Sonar System in Seafloor Habitat Mapping. Australia. Centre for marine science and technology, curtin university, perth, Australia.

Pemerintah Republik Indonesia. (2011). Peraturan Pemerintah No.38 Tahun 2011, Tentang Sungai. Jakarta. Kementerian Sekretariat Negara Republik Indonesia.

Rosdynur, Z.S. (2012). Pekerjaan Survei Hidrografi dan Perencanaan Alur Pelayaran dalam Usaha Transportasi Hasil Pertambangan Batubara. Bandung: Teknik Geodesi dan Geomatika ITB.

Syahrial, R. (2009). Analisis Peruntukan Lahan Daerah Aliran Sungai (DAS) Belawan Kaitannya Dengan Perencanaan Tata Ruang. Medan: Sekolah Pascasarjana Universitas Sumatera Utara.
Wellenhof, B.H., Helmut Moritz. (2005). Physical Geodesy. Institut für Navigation und Satellitengeodäsie Technische Universität Graz, Graz, Austria.

Yuwono. (2005). Buku Ajar Hidrografi-1. Survei Hidrografi. Surabaya: Teknik Geodesi ITS. 